\title{
Algunos aportes para el estudio del Artículo 26 de la Carta de las Naciones Unidas
}

Por Felipe E. Mac Gregor S. J. (1)

Introduccićn

Agradezco la oportunidad de participar en este fónum (2) en el que he escogido como materia de estudio el art. 26 de la Carta de las Naciones Unidas. Varias razones me han decidido a hacer esta elección.

Es la primera que el artículo 26 presenta, en mi opinión, uno de los aspectos más interesantes de la Carta de los Derechos Humanos de las Na. ciones Uniclas, a saber, el reconocimiento de las varias instituciones modeladoras y coordinadoras del ejercicio de los derechos individuales; lo que se expresa en el caso del art. 26 en el inciso 3) que dice así: "Los padres tendrán derecho preferente a escoger el tipo de educación que habrá de darse a sus hijos".

También ha pesado gravemente para decidir mi elección la incalculable importancia doctrinal del derecho reconocido en el art. 26, que está tan vinculado a los artículos 18,19 y 27; finalmente y como consecuencia del esclarecimiento de los alcances del art. 26 se presenta la urgencia que existe en muchos países de acomadar las disposiciones positivas de las legislaciones vigentes a las exjgencias que la aceptación de este derecho impone.

En contraste con la Declaración de los Derechos Humanos de la Revolución Francesa, de fecha 5 de Octubre de 1789, en la Carta de Ias Na. ciones Unijas de 10 de diciembre de 1948, se recońoce la existencia de una serie de instituciones sociales. El Art. 16 en el inciso 3, dice: "La familia es el elemento natural y fundamental de la Sociedad y tiene derecho a la protección de la sociedad y del Estado"; el art. 23 en el inciso 3. y el art. 25 en el inciso 1 , hablan también de la institución familiar.

El art. 29 habla de la "comunidad" y su relación a la persona; lo que significa una referencia concreta a comunidades locales, por ejemplo.

Entre la concepción de la Carta de la Revolución Francesa que relacionaba exclusivamente al individuo con el Estado, hay en esta nueva

(1) Rector de la Pontificia Universidad Católica del Perú.

(2) Colegio de Abagadon de Lima (23.9.1966). 
formulación de los Derechos Humanos el recanocimiento de instituciones. sociales "intermedias".

La Carta de las N. U. se refiere frecuentemente al Estado y en el. art. 28 extiende su visión no sólo al orden familiar, local o de la cornunidad. estatal, sino también al orden internacional: "Toda persona tiene derecha a que se establezca un arden social e internacional en el que los derechos. y libertades proclamados en esta Declaración se hagan plenamente efectivos.".

La importancia doctrinal del derecho reconocido en el art. 26 y sus correlativos 18,19 y 27 se desprende de la lectura misma de su texto.

La interrelación de este derecho con los derechos de las sociedades. como la Sociedad Familiar, Sociedad Religiosa, comunidad local es también evidente.

El derecho que consideramos significa, con relación a la persona, la manera de capacitarla para el ejercicio del derecho que el ant. 18 de la Carta de jas Naciones Unidas reconoce, lo mismo que el reconocido por el art. 19.

El reconocimiento de estos derechos consagrados por los Arts. 18. y 19 de la Carta de las N. Ũ. es uno de los fundamentos de la "Declaración de los Derechos del hombre y del ciudadano" del 5 de Octubre de 1789. Dice esa Declaración:

Art. 10.-Ningún hombre debe ser inquietado por sus opiniones. aunque sean religiosas, con tal que su manifestación no turbe el orden público establecido por la ley.

Art. 11.-La libre comunicación de los pensamientos y de las opiniones es uno de los derechos más preciosos del hombre: todo ciudadano. en su consecuencia, puede hablar, escribir, imprimir libremente, debiendo sí responder de los abusos de esta libertad en los casos determinados por la ley.

Los artículas aludidos (18 y 19) de la Carta de las Naciones Unidas. suponen al hombre maduro $y$ en pleno ejercicio de sus derechos naturales o civiles; pero existe un proceso de adaptación por el cuál se llega a esa plena madurez; ese proceso de diversa manera realizada recibe el nombre de educación.

En la educación hay la asimilación del saber objetivo ya adquirido Y hay también el trabajo o la preparación para el trabajo de investigar, indagar, o explorar la realidad no conocida.

No sólo adquirir el saber (contenido intelectual) constituyen o determinan la educación. también son parte de ella aprender a "gozar de las. artes"; (Declaración N. U. art. 27) además la educación tiene necesariamente un profundo sentido o contenido religioso.

Como la preparación para la investigación científica o la libertad. personal de opinión, también para la educación religiosa, debe comprenderse que el proceso de maduración a que ayuda la educación es el camino para la plena libertad a que antes hemos aludido $y$ que se consagra en el out. 18 (Carta N. U.).

En vez de detenerme a subrayar la importancia de la educación para capacitar $\alpha$ "la libertad de investigar" o para "la expresión artística" deseo referirme, más particularmente, $\alpha$ la relación entre la educación $Y$ 
las convicciones religiosas.

Hay, además de otras razones, una de orden positivo y muy actual que me invita a hacerlo.

Las Naciones Unidas tienen una Comisión permanente para el estudio de los Derechos Humanos; esta Comisión viene trabajando desde hace algunos años en el texto de un pacto que deben firmar las naciones para la eliminación de toda fórmula de discriminación religiosa.

El documento se denomina "Convenio para la eliminación de todas las formas de intolerencia religiosa".

El preámbulo y los tres primeros artículos de este Convenio fueron aprobados en Ginebra en 1965 por la Comisión de Derechos Humanos de las Naciones Unidas.

Del 8 de marzo al 8 de abril de 1966 en Nueva York se han estudiado los artículos $4^{\circ}, 5^{\circ}, 6^{\circ}$ y $7^{\circ}$. El texto de estos artículos definitivamente aprobados por la Comisión es el siguiente:

\section{ARTICLE IV:}

1. Les Etats parties s'engagent á respecter le droit qu'ont les parents et, le cas échéant, les tuteurs légaux d'élever dans la religion ou dans la conviction de leur choix leurs enfants ou leurs pupilles qui ne sont pas encore capables $d^{*}$ exercer la liberté de choix garantie en vertu du paragraphe l-a' de l'article III.

2. L'exercice de ce droit implique pour les parents et les tuteurs légaux l'obligation d'inculquer á leurs enfants ou á leurs pupilles des sentiments de tolérance pour la religion ou la conviction d'autrui et de les protéger contre toute doctrine ou pratique inspirée par l'intolérance religieuse ou la discrimination d'aprés la religion ou la conviction.

3. Dans le cas d'un enfant qui a été privé de ses parents, les voeux exprimés ou présumës de ces derniers seront dúment pris en considération.

4. Lors de l'application des dispositions du présent article, I'intérét supérieur de l'enfant sera le principe dominont pour ceux qui portent la responsabilité d'élever et d'éduquer l'enfant.

\section{ARTICLE V:}

"Les Etats parties s'engagent á adopter inmédiatement des mesures efficaces, notamment dans les domaines de l'enseignement, de l'éducction, de la culture et de l'information, en vue de combattre les préjugés, tels que l'antisémitisme qui conduisent á l'intolérance religieuse et á la discrimination fondée sur la religion ou la conviction, et de favoriser et d'en. courager, dans l'intérét de la paix universelle, la compréhension, la tolérance, la coopération et l'amitié entre les nations, les groupes et les particuliers. quelles que soient les différences de religion ou de conviction, conformément aux buts et principes de la Charte des Nations Unies, la Déclaration universelle des droits de l'homme et la présente Convention." 


\section{ARTICLE VI:}

"1. Conformément aux obligations fondamentales énoncées á l'article 2, les Etats parties s'engagent \& adopter des mesures efficaces pour prévenir et éliminer la discrimination fondée sur la religion ou la conviction, noIamment par la promulgation ou l'abrogation des lois ou des dispositions réglementaires, s'il est nécesscire, pour interdire cette discrimination de la part de toute personne, de tout groupe ou de toute organisation.

2. Les Etats parties s'engágent á ne pas appliquer une politique, ni á mettre ou maintenir en vigueur des lois ou des dispositions réglementaires de nature á apporter des restrictions ou á faire obstacle á la liberté de conscience, de religion et de conviction ou au libre et plein exercice de cette liberté, et á n'exercer contre aucune personne, aucun groupe ou aucune organisation, une discrimination fondée sur l'appartenance ou la non-appartenance, l'adhésion ou la non-adhésión á une religion ou á une conviction ou sur la pratique ou la non-pratique d'une religion ou d'une conviction".

\section{ARTICLE VII:}

"Les Etats parties s'engagent ó assurer ó toute personne l'égalité dewant la loi sans discrimination aucune dans l'exercice du droit á la liberté de pensée, de conscience, de religion, ou de conviction et une égale protection de la loi contre toute discrimination fondée sur la religion ou la conviction."

Después de un mes de deliberaciones, la Comisión ha dejado para su próxima sesión la discusión de los cinco artículos restantes indicando que este asunto tiene la "priorité la plus élevée".

Es doctrinalmente interesante este asunto porque ha presentado de nuevo en el más alto nivel la confrontación de la dual fundamentación de los derechos positivos: Una se inspira y tiene su raíz profunda en el reco. nocimiento de la persona humana como la fuente de donde los derechos emanan. La otra hace del Estado el fundamento principal de la Sociedad y reduce el derecho a la comunicación por el Estado a los individuos o grupos, de poderes que son del Estado y provienen de él. Naturalmente que no se presenta siempre la discusión en términos tan claros y alternativas tan precisas.

Es iluminador leer las relaciones de las discusiones sobre los textos del Cónvenio antes aludido: como es también significativo el resultado de las votaciones. El art. IV que copiamos antes fué aprobado en el seno de la Comisión después de una semana de discusiones, por 16 votos y 5 abstenciones. Argentina y Suecia se abstuvieron porque no creían que el artículo tuviera relación con la Convención -era innecesario. La URSS, Ukerania y Polonia se abstuvieron por las razones doctrinales arriba indicadas. 


\section{I}

El ejercicio práctico por la familia del derecho que el àrt. 26 de la Carta reconoce está condicionado por las leyes y disposiciones autoritativas. de los diversos países.

La confrontación entre la legisiación, positiva y este derecho supraconstitucional, si cabe la expresión, ha sido hecho, por ejemplo en el Seminario sobre Libertad de Enseñanza que se realizó en Setiembre de 1957 y tuve el honor de presidir. Las ponencias y conclusiones del Seminario están publicadas en el $\mathrm{N}^{\circ} 90$ del Vol. XVI de la. Revista Interamericana de Educación (Bogotá-Colombia).

Para indicar solamente algunas de las consecuencias más obvias del derecho que venimos comentando: elegir un sistema de educación, significa que hay varios entre los que puede elegirse. Lo que equivale a decir que no existe monopolio pedagógico: no hay una sola manera, ni una sola ordenación de estudios secundarios, por ejemplo.

Significa, además, que la elección, o posibilidad de ella, debe ser auténtica. No hay elección posible si no se tiene los medios de hacerla. Si un sistema de enseñanza es gratuito $y$ otro pagado se mediatiza la opción a los recursos económicos; las aplicaciones pueden irse multiplicando: artículos como el 372 de la Ley de Educación Pública (Ley 9359) son incon-sistentes con el art. 26 de la Carta de las Naciones Unidas. 